\title{
Woody Plant Species Diversity of Gechi In-situ Forest Conservation Site, Sekela District, North Western Ethiopia
}

\author{
Tensay Ayalew ${ }^{1}$, Sisay Alemu ${ }^{2}$, Edeget Merawi ${ }^{1, ~ * ~}$ \\ ${ }^{1}$ Ethiopian Biodiversity Institute, Bahir Dar Biodiversity Center, Bahir Dar, Ethiopia \\ ${ }^{2}$ Ethiopian Biodiversity Institute, Addis Ababa, Etrhiopia
}

Email address:

edegetmerawi@gmail.com (E. Merawi)

${ }^{*}$ Corresponding author

\section{To cite this article:}

Tensay Ayalw, Sisay Alemu, Edeget Merawi. Woody Plant Species Diversity of Gechi In-situ Forest Conservation Site, Sekela District, North Western Ethiopia. Ecology and Evolutionary Biology. Vol. 4, No. 4, 2019, pp. 60-71. doi: 10.11648/j.eeb.20190404.13

Received: May 29, 2019; Accepted: October 30, 2019; Published: November 11, 2019

\begin{abstract}
The study was conducted at Gechi in-situ forest conservation site to investigate woody plant species diversity. To collect the inventory data, a systematic and predetermined sampling system was followed. The main objectives of the study was to undergo inventory of the indigenous woody species, assessing the regeneration status, to determine the floristic composition and set the priority list of woody plant species for the vegetation of the area. Study was conducted during in January 2019. Gechi in-situ conservation site land feature was valley the transect line was laid along the valley ridge. All ten transects ware laid from west to east direction with forward bearing of $32^{\circ}$, between transects $150 \mathrm{mt}$ distance and also the quadrates were established with regular interval of $200 \mathrm{~m}$ from each other. In general, a total of three transects, 31 quadrates and 62 sub-quadrates were used to collect the inventory data from the Gechi in-situ site vegetation. From the inventoried a total of 47 woody plant specimens were collected; out of which 46 specimens were identified to the species level. Major threat of the Gechi forest recording during the study were $1.1 \%$ clearing for agriculture, $31.1 \%$ and $34.4 \%$ of the negative impacts were attributed by browsing and grazing respectively with moderate and intensive (heavy) levels and also $33.3 \%$ of forest was cutting of Bamboo for fence construction with the intensity of moderate to intensive disturbance level. To overcome forest disturbance proper conservation has to be taken to solve the problems and prevent the forest from forest disturbance factors.
\end{abstract}

Keywords: Seedling, Inventory, Conservation, Disturbance

\section{Introduction}

Ethiopia has a great geographical diversity, ranging from 100 $\mathrm{m}$ below sea level to $4600 \mathrm{~m}$ a. s. 1 . The highlands, defined as above $1500 \mathrm{~m}$ a. s. 1 ., account for $45 \%$ of the total land area of the country. [2] The lowlands which lie below $1500 \mathrm{~m}$ a. s. 1., account for $55 \%$ of the total land area in the country. Forests and/or vegetation in these wide agro-ecological zones provide socio-cultural, economic, environmental and biodiversity conservation importance to human beings. However, tropical forests are vanishing and being degraded rapidly, due to accelerated growth of the human population, which results in the conversion of forestland to agricultural land and excessive exploitation of forests for fuel wood and construction materials, as a result, $35 \%$ of the Ethiopian land area that might once have been covered by natural high forests was reduced to $15.7 \%$ in the $2018[1,6]$. Genetic variation enables both natural evolutionary change and artificial selective breeding to occur [14]. In a seminal work on the measurement of diversity, [15] introduced the concepts of alpha, beta, and gamma diversity. The local-determination hypothesis of species diversity [11], which predicts similar species diversity in similar habitats, has also been challenged. Forest degradation in quality (species reduction) and quantity (shrinkage in volume/area) are threatening the biodiversity resources of the country. This reality is true in all highland and lowland ecological systems. In line with this [16], on which this technical report has focused on, has reported that the Acacia-Commiphora (small-leaved) deciduous woodlands have been seriously depleted in recent years for wood and charcoal production. To counteract this problem in general, the economic policy of Federal Government of Ethiopia has identified deforestation as one of the major problems to be tackled by the conservation strategy of the country. To achieve this in a sustainable way, setting priorities for the threatened 
species in each vegetation types is indispensable. Therefore, this study deals with the inventory of the Gechi in-situ conservation site which is moist evergreen afro-alpine forest (MAF). The main objectives of the study was inventory the indigenous woody species, assessing the regeneration status and determine the floristic composition and set the priority list of the woody plant species for the vegetation of the area.

\section{Materials and Methods}

\subsection{Description of the Study Area}

Sekela District is located in West Gojjam Zone of Amhara Region at about $163 \mathrm{~km}$ to the South east of Bahir dar town and $35 \mathrm{~km}$ from Tilili to the North direction. The District is $768.83 \mathrm{~km}^{2}$ in area [12]. The vegetation, which was inventoried, was located nearby the Sekela town (the main town of the District) between the geographical coordinates of $11^{0} 03^{\prime} 11.6^{\prime \prime}-11^{0} 03^{\prime} 54.1^{\prime \prime} \mathrm{N}$ latitudes and $37^{0} 16^{\prime} 03.0^{\prime \prime}-37^{\circ} 16^{\prime} 29.5^{\prime \prime}$ E longitudes. The vegetation extends up to $2 \mathrm{~km}$ along east to west direction of the forest and $17 \mathrm{~km}$ far from Gish Abay town to North direction.

\subsection{Materials}

Materials used during the study were Digital camera, GPS, meter, caliper, hypeso meter, laptop computer and note book.

\subsection{Methodology}

\subsubsection{Sampling Procedure}

i. Sampling system and Design
To get the general view about the vegetation to be inventoried, the team has traveled around and made reconnaissance survey in January 2019 during the first and second days of the inventory work. In view of this, preliminary information on topographic features (slope, aspect and altitudinal gradient) and on how to layout transects on the ground were gathered (Table 1). To collect the inventory data, a systematic and predetermined sampling system was followed. After the arranging of optimum directions of transects were determined, to assess the vegetation and capture the diversity in reliable way, a straight transects were used. For this, at the beginning of the navigation the bearings were fixed using GPS. To collect the data the main quadrate of $50 \mathrm{~m} \mathrm{X} \mathrm{10m} \mathrm{size;} \mathrm{and} \mathrm{a} \mathrm{sub-quadrate} \mathrm{of} 10 \mathrm{~m} \times 2 \mathrm{~m}$ size were established within the main quadrate at the longest sides of both ends.

\section{ii. Transect and Quadrate layout}

Generally Gechi in-situ conservation site land feature was valley the transect line was laid along the valley ridge (i.e. start plot from top of the valley goes to the bottom and also goes to valley top) (see figure 1). All ten transects were laid from West to East direction with forward bearing of 320, between transects $150 \mathrm{mt}$ distance and also the quadrates were established with regular interval of $200 \mathrm{~m}$ from each other as recommended EBI forest manual. The regeneration status of the woody plant species was assessed from sub-quadrates that were established as aforementioned in the sampling design. In general, a total of three transects, 31 quadrates and 62 sub-quadrates were used to collect the inventory data from the Gechi in-situ site vegetation.

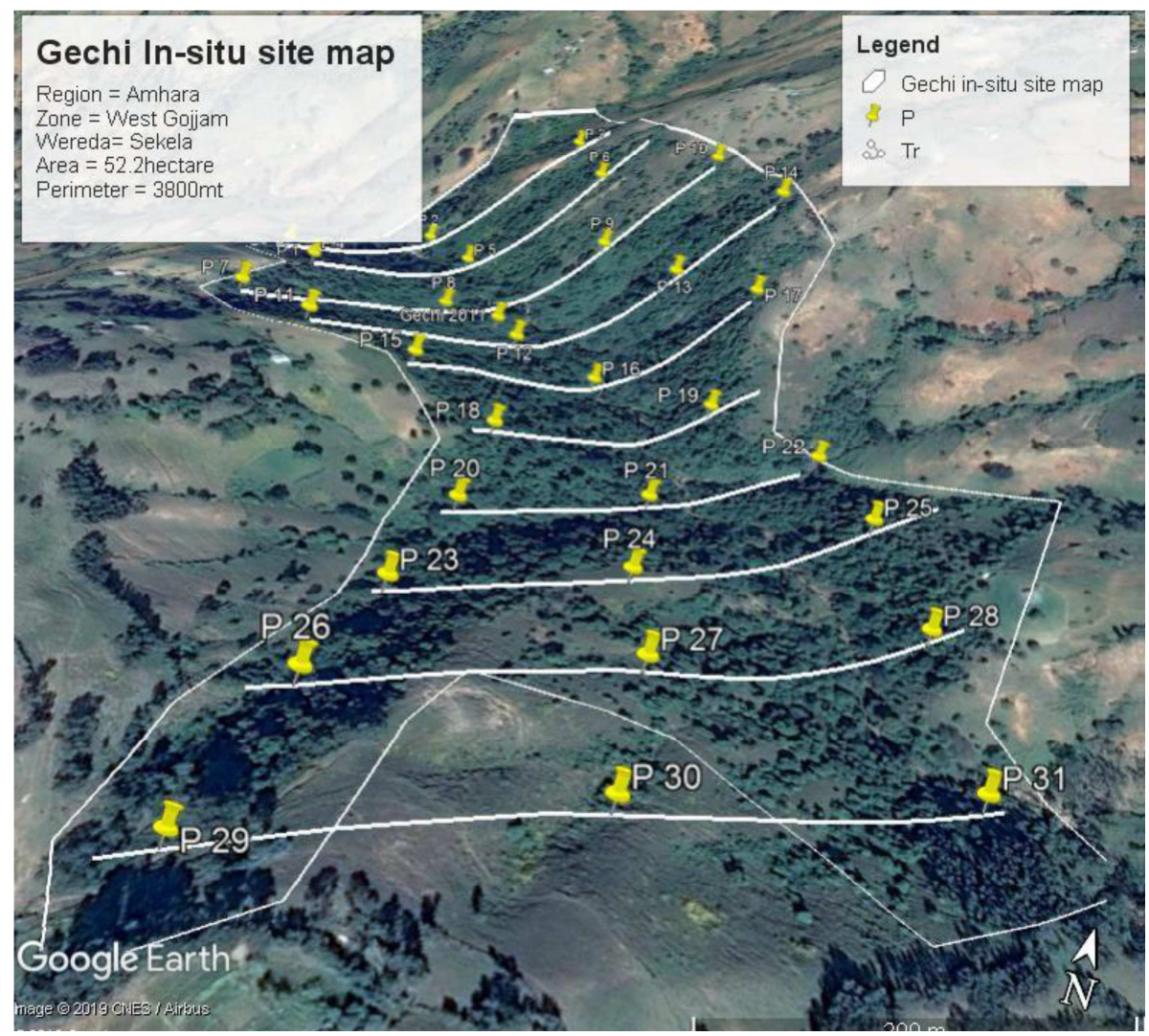

Figure 1. Gechi in-situ site data collection plot design. 
Table 1. Gechi in-situ site data collection geo-referenced points.

\begin{tabular}{|c|c|c|c|c|c|c|c|}
\hline Plot name & Latitude & Longitude & Altitude & Plot name & Latitude & Longitude & Altitude \\
\hline P 1 & $11^{\circ} 3{ }^{\prime} 39.72^{\prime \prime N}$ & $37^{\circ} 16^{\prime} 1.70^{\prime \prime E}$ & 2594 & P 17 & $11^{\circ} 3{ }^{\prime} 36.67 " \mathrm{~N}$ & $37^{\circ} 16^{\prime} 20.711^{\prime E}$ & 2675 \\
\hline P 2 & $11^{\circ} 3{ }^{\prime} 43.77^{\prime \prime N} \mathrm{~N}$ & $37^{\circ} 16^{\prime} 5.85^{\prime \prime E}$ & 2564 & P 18 & $11^{\circ} 3 ' 27.70 " \mathrm{~N}$ & $37^{\circ} 16^{\prime} 15.20^{\prime \prime E}$ & 2673 \\
\hline P 3 & $11^{\circ} 3^{\prime} 48.76 " \mathrm{~N}$ & $37^{\circ} 16^{\prime} 11.00^{\prime \prime E}$ & 2644 & Р 19 & $11^{\circ} 3{ }^{\prime} 31.95 " \mathrm{~N}$ & $37^{\circ} 16^{\prime} 20.30^{\prime \prime E}$ & 2638 \\
\hline P 4 & $11^{\circ} 3^{\prime} 36.76^{\prime \prime} \mathrm{N}$ & $37^{\circ} 16^{\prime} 4.64^{\prime \prime E}$ & 2642 & P 20 & $11^{\circ} 3{ }^{\prime} 24.31 " \mathrm{~N}$ & $37^{\circ} 16^{\prime} 15.59^{\prime \prime E}$ & 2683 \\
\hline P 5 & $11^{\circ} 3{ }^{\prime} 41.06 " \mathrm{~N}$ & $37^{\circ} 16^{\prime} 8.75^{\prime \prime} \mathrm{E}$ & 2580 & P 21 & $11^{\circ} 3 ' 27.22 " \mathrm{~N}$ & $37^{\circ} 16^{\prime} 19.611^{\prime E}$ & 2639 \\
\hline P 6 & $11^{\circ} 3^{\prime} 45.17^{\prime \prime N}$ & $37^{\circ} 16^{\prime} 13.04 " \mathrm{E}$ & 2658 & Р 22 & $11^{\circ} 3{ }^{\prime} 30.40^{\prime \prime} \mathrm{N}$ & $37^{\circ} 16^{\prime} 23.62^{\prime \prime E}$ & 2635 \\
\hline P 7 & $11^{\circ} 3{ }^{\prime} 31.85^{\prime \prime} \mathrm{N}$ & $37^{\circ} 16^{\prime} 5.14 " \mathrm{E}$ & 2688 & P 23 & $11^{\circ} 3 ' 20.39^{\prime \prime} \mathrm{N}$ & $37^{\circ} 16^{\prime} 15.82^{\prime \prime} \mathrm{E}$ & 2725 \\
\hline P 8 & $11^{\circ} 3{ }^{\prime} 36.38^{\prime \prime} \mathrm{N}$ & $37^{\circ} 16^{\prime} 9.88^{\prime \prime} \mathrm{E}$ & 2607 & Р 24 & $11^{\circ} 3{ }^{\prime} 23.41 " \mathrm{~N}$ & $37^{\circ} 16^{\prime} 20.13^{\prime \prime E}$ & 2676 \\
\hline P 9 & $11^{\circ} 3^{\prime} 40.96 " \mathrm{~N}$ & $37^{\circ} 16^{\prime} 14.41^{\prime \prime E}$ & 2633 & Р 25 & $11^{\circ} 3 ' 27.33 " \mathrm{~N}$ & $37^{\circ} 16^{\prime} 25.21^{\prime \prime E}$ & 2659 \\
\hline P 10 & $11^{\circ} 3{ }^{\prime} 44.35^{\prime \prime} \mathrm{N}$ & $37^{\circ} 16^{\prime} 17.82^{\prime \prime E}$ & 2704 & Р 26 & $11^{\circ} 3^{\prime} 16.87 " \mathrm{~N}$ & $37^{\circ} 16^{\prime} 16.16^{\prime \prime E}$ & 2768 \\
\hline P 11 & $11^{\circ} 3{ }^{\prime} 30.01 " \mathrm{~N}$ & $37^{\circ} 16^{\prime} 8.63^{\prime \prime E}$ & 2703 & P 27 & $11^{\circ} 3^{\prime} 20.11 " \mathrm{~N}$ & $37^{\circ} 16^{\prime} 21.25^{\prime \prime E}$ & 2714 \\
\hline P 12 & $11^{\circ} 3{ }^{\prime} 34.43^{\prime \prime N}$ & $37^{\circ} 16^{\prime} 13.28^{\prime \prime E}$ & 2623 & Р 28 & $11^{\circ} 3{ }^{\prime} 23.62 " \mathrm{~N}$ & $37^{\circ} 16^{\prime} 26.59^{\prime \prime} \mathrm{E}$ & 2674 \\
\hline P 13 & $11^{\circ} 3^{\prime} 38.73^{\prime \prime N}$ & $37^{\circ} 16^{\prime} 17.65^{\prime \prime E}$ & 2651 & Р 29 & $11^{\circ} 3^{\prime} 13.28 " \mathrm{~N}$ & $37^{\circ} 16^{\prime} 16.58^{\prime \prime E}$ & 2807 \\
\hline P 14 & $11^{\circ} 3^{\prime} 41.72 " \mathrm{~N}$ & $37^{\circ} 16^{\prime} 20.65^{\prime \prime E}$ & 2706 & Р 30 & $11^{\circ} 3^{\prime} 16.26^{\prime \prime} \mathrm{N}$ & $37^{\circ} 16^{\prime} 21.70^{\prime \prime E}$ & 2760 \\
\hline P 15 & $11^{\circ} 3 ' 29.31 " \mathrm{~N}$ & $37^{\circ} 16^{\prime} 12.26^{\prime \prime} \mathrm{E}$ & 2695 & P 31 & $11^{\circ} 3^{\prime} 19.76 " \mathrm{~N}$ & $37^{\circ} 16^{\prime} 27.68^{\prime \prime E}$ & 2678 \\
\hline P 16 & $11^{\circ} 3{ }^{\prime} 32.93 " \mathrm{~N}$ & $37^{\circ} 16^{\prime} 16.43^{\prime \prime E}$ & 2622 & & & & \\
\hline
\end{tabular}

\subsubsection{Data Collection}

i. Physiographic and soil data

Prior to the collection of the vegetation data, from each quadrate geographical coordinates and altitude were recorded using GPS. Simultaneously, topographic characteristics including slope gradient and depth, slope position and aspect were collected following the woody plant species diversity assessment field manual prepared by IBC. In addition, observational data on soil type, texture and color were also collected. These data were registered on the same format used for vegetation inventory.

ii. Vegetation data

To collect the vegetation data two pre-structured; woody plant species inventory and regeneration status assessment forms were used. However, in the beginning, the physiognomy and type of the vegetation were described before going for collecting the vegetation data. Thereafter, for each woody plant species appeared in the sample plots and for trees and shrubs having the DBH $2.5 \mathrm{~cm}, \mathrm{DSH} / \mathrm{DBH}$ was measured using the graduated Caliper while the data of total height was taken on ocular estimation. For shrubs possessing several stems rising from below DBH, each branch was measured for DSH/ DBH and height as individual stem and number of stems were also counted duly. Moreover, together with this, the growth habit and number of stems of each species existing in the plots were described and recorded. The types of the woody plant species were recorded using local names. On the other hand, the data of the saplings and seedlings of woody plant species were collected from the sub-quadrates as described above. Simultaneously, plant specimens were collected and pressed in the field using the plant presser. These specimens were dried, identified, mounted and kept at the Herbarium of Ethiopian biodiversity institute.

\section{Results and Discussions}

\subsection{Environmental Data}

\subsubsection{Land Use/Land Cover}

The major land cover types of the area are mixed forest (at the upper and middle parts of the slope), and Bamboo at the lower and river bank area. These cover types are mainly dominated by different broad leaved species. In the vegetation area browsing and grazing, clearance for agricultural land, wood cutting for house construction and traditional beekeeping or hanging beehives on the trees for honey production are the major land use type. The types of crops cultivated are Wheat, Barely, Maize, Teff, Potato and Lupine in rare cases.

\subsubsection{Forest Disturbance}

Both human and Livestock (Cattle, Sheep and Donkey) interferences have caused disturbance impacts on the vegetation. Of these, encroachment and agriculture, Browsing and grazing are the major attributing factors towards the degradation of the vegetation of the area. However, the level of impacts that these factors cause varies. About $1.1 \%$ of the forest disturbance was caused during clearing the forest for agriculture and the intensity of the impact here is heavy disturbance. While, about $31.1 \%$ and $34.4 \%$ of the negative impacts were attributed by browsing and grazing respectively with moderate and intensive (heavy) levels and also $33.3 \%$ of forest was cutting of Bamboo for fence construction with the intensity of moderate to intensive disturbance level (Table 2).

Table 2. Proportion of the level of factors of forest disturbance.

\begin{tabular}{lllllll}
\hline $\begin{array}{l}\text { Factors of forest } \\
\text { disturbance }\end{array}$ & Disturbance Scale & & & & \\
\cline { 2 - 7 } & $\mathbf{1}$ (Negligible) 0-20\% & $\mathbf{2}$ (Light) 20-40\% & $\mathbf{3}$ (Moderate) 40-55\% & $\mathbf{4}$ (Intensive) 55-70\% & $\mathbf{5}(\mathbf{H e a v y )}$ above 70\% Total (\%) \\
\hline Agriculture & & & & 1.1 & 1.1 \\
Browsing & & 25.55 & 3.33 & 2.22 & 31.1 \\
Grazing & 2.22 & 25.22 & 4.44 & 2.22 & 34.4 \\
Logging & 2.22 & 14.43 & 14.43 & 2.22 & 33.3 \\
\hline
\end{tabular}




\subsubsection{Geophysical Aspects}

As indicated in Table 3, the data were taken from four topographic aspects and at five slope positions (2543-2806m. a. s. 1.) and within the $12-68 \%$ slope gradients.

Table 3. Topographic features and level of forest disturbance.

\begin{tabular}{llllllll}
\hline $\begin{array}{l}\text { Slope } \\
\text { position }\end{array}$ & $\begin{array}{l}\text { Altitude } \\
\text { (m. a. s. I.) }\end{array}$ & $\begin{array}{l}\text { Slope gradient } \\
(\%)\end{array}$ & Aspect & $\begin{array}{l}\text { No of } \\
\text { quadrates }\end{array}$ & $\begin{array}{l}\text { Forest disturbance } \\
\text { types }\end{array}$ & $\begin{array}{l}\text { Forest disturbance } \\
\text { intensity }\end{array}$ & $\begin{array}{l}\text { Proportion of } \\
\text { sample plots (\%) }\end{array}$ \\
\hline Upper & $2721-2806$ & $25-68$ & NE, N, SW, W & 15 & & Moderate & 48.39 \\
Middle & $2631-2721$ & $21-45$ & NE, S, SW, NW, N & 8 & Browsing, Grazing & Intensive & 25.81 \\
Lower & $2543-2630$ & $26-60$ & N, NE, SW & 8 & and Agriculture & Light intensive & 25.81 \\
Total & & & & 31 & & & 100 \\
\hline
\end{tabular}

\subsection{Floristic Composition}

From the inventoried Gechi In-situ site conservation forest a total of 47 woody plant specimens were collected; out of which 46 specimens were identified to the species level, while 1 specimens were not identified and they will be taken to National Herbarium of Addis Ababa University for identification. The identified specimens belong to 41 genera and 31 families. The most frequent genera in the Gechi forest were Dovyalis (Flacourtiaceae), Maytenus (Celastraceae) and Vernonia (Asteraceae) respectively. On the other hand the family of these genera is also the most frequent and diverse in the inventoried wood land. From each respective genera, Dovyalis abyssinica, Dovyalis verrucosa; Maytenus arbutifolia, Maytenus obscura; Vernonia amygdalina and Vernonia auriculifera were found to be the most diverse woody plant species. Regardless of the diversity of families, in the area, Bersama abyssinica, Nuxia congesta, Maytenus obscura, Arundinaria alpina, Brucea antidysenterica, Measa lanciolata, Dovyalis verrucosa, Maytenus obscura, Prunus africana, Vernonia amygdalina, Euphorbia abyssinica Allophylus abyssinicus and Rosa abyssinica were the widely appeared woody plant species. Meanwhile, the result of the study depicted that Osyris quadripartita, Hagenia abyssinica, Ekebergia capensis, Myrica salicifolia, Dovyalis abyssinica, Pittosporum viridiflorum, Capparis tomentosa, Discopodium penninervium, Dombeya torrida, and Schefflera abyssinica were the medium ones in diversity from the woody plant species assessed. On the contrary, Acacia abyssinica, Amedmado, Buddleja polystachya, Clausena anisata, Clematis longicauda, Erica arborea, Hibiscus macaranthus, Maytenus arbutifolia, Myrsine africana, Rubus steudneri, Solanecio gigas, Urera hypselodendron and Vernonia amygdalina were the least frequent and diverse in the Gechi in-situ conservation site forest. The distribution of the plant species in terms of the growth forms or habits was resulted as Trees, 21 in number of species (44.7\%), Shrubs, 19 in number of species $(40.4 \%)$ and climber or Lianas, 7 in number of species which accounts to $14.9 \%$ from the whole growth habits. However, since this floristic composition does not include that of the herbaceous plant species, it needs further study to conclude about the complete floristic composition of the woodland.

\subsection{Structure}

\subsubsection{Species Dimensions}

The maximum height attained in the Gechi forest was 30 $\mathrm{m}$ while the maximum DBH/DSH was $72 \mathrm{~cm}$ represented by the Hagenia abyssinica tree species. This tree species is also the highest in terms of mean height $(14.71 \mathrm{~m})$ and mean $\mathrm{DBH} / \mathrm{DSH}(34.82 \mathrm{~cm})$. The maximum number of stems sampled and measured was for those tree species that are the most diverse or frequently appearing in the inventoried forest. On the other hand, the least size of DSH/DBH and total height recorded was $3.4 \mathrm{~cm}$ and $2.7 \mathrm{~m}$ respectively.

\subsubsection{Species Frequency}

The result of the study showed that the variation of the species frequency ranges between $3.23-77.42 \%$. This implies that there is a high heterogeneity in species distribution in the Gechi in-situ site conservation forest. Among these, Bersama abyssinica (77.42\%), Nuxia congesta (61.29\%), Apodytes dimidiata (51.61\%), Arundinaria alpine, Measa lanciolata and Brucea antidysenterica (45.16\%) respectively, and Dovyalis verrucosa (41.94\%) the most frequently appearing or are the most widely distributed woody plant species. Moreover, Maytenus obscura, Prunus africana, Vernonia auriculifera (38.71\%), Allophylus abyssinicus, Euphorbia abyssinica and Rosa abyssinica (35.48\%), Osyris quadripartita (32.26\%), Hagenia abyssinica (25.81\%), are the woody species possessing the higher frequency next to the aforementioned species which attained the highest frequency. On the other hand, Acacia abyssinica, Amedmado, Buddleja polystachya, Clausena anisata, Clematis longicauda, Erica arborea, Hibiscus macaranthus, Maytenus arbutifolia, Myrsine africana, Rubus steudneri, Solanecio gigas, Urera hypselodendron and Vernonia amygdalina are the species which are uniformly the lowest in frequency distribution (3.23\%) when compared to the frequency of the remaining species. Hence, there is a high variation in species 15 distribution between the abovementioned groups of species that showed the highest and the lowest frequency. Nonetheless, the majority of the species fall between the frequency range of $6.45-19.35 \%$. In other words, when the distributions of species were interpreted in terms of frequency classes, no species was fallen in frequency class-A (81-100\%). It is only two species, Bersama abyssinica and Nuxia congesta, which was 
belonged to the B frequency class (61-80\%). Further, as illustrated in Figure 2, about $13.5 \%$ the species was included under frequency class $\mathrm{C}(41-60 \%) ; 21.6 \%$ under frequency class D (21-40\%) while $59.5 \%$ of the species were categorized under frequency class E (1-21\%). Therefore, the falling of highest percentage (or number of species) under low value frequency class implies as the distribution of the species is in the woodland is not generally high.

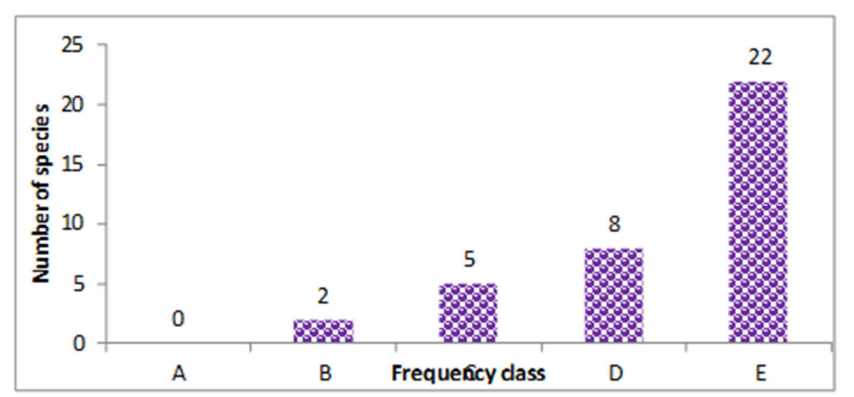

Figure 2. The number of species by frequency class.

\subsubsection{Species Density}

The species density recorded in the woodland ranges between $0.65-4816.77$ per ha. The variation of the relative density of the species is also between $0.01-84.40 \%$. The least species density was for Acacia abyssinica, Amedmado, Clausena anisata and Myrsine africana while the highest species density ( $>100$ per ha) was for Arundinaria alpine (4816.77) and Euphorbia abyssinica (122.58). This result Pointed out that there is a significant variation among the individual tree/shrub species in density per ha.. In the inventoried forest, the total species density per ha was 5707.12. To summarize, the species density was organized by density classes as shown in Table 4 . Here, the majority of the species $(55.81 \%)$ was belonged to density class D.

The species densities per ha with the diameter size greater than $10 \mathrm{~cm} \mathrm{DSH/DBH}$ and greater than $20 \mathrm{~cm} \mathrm{DSH/DBH}$ are 211 and 99.38 respectively and their ratio is 44.16 . This implies that the number of stems per hectare was higher for species of smaller diameter size than for species of greater diameter size.

Table 4. Species density class and the distribution of species.

\begin{tabular}{lllll}
\hline Species density class & Total density & Relative density & Number of species \\
\hline A $(>100)$ & 4816.77 & 86.55 & 2 & Proportion (\%) \\
B $(50.1-100)$ & 400.63 & 7.02 & 6 & 4.65 \\
C (20.1-50) & 227.75 & 2.34 & 7 & 13.95 \\
D $(1-20)$ & 136.79 & 4.03 & 24 & 16.28 \\
E $(<1)$ & 2.60 & 0.04 & 4 & 55.81 \\
Total & 5707.12 & 100 & 43 & 9.30 \\
\hline
\end{tabular}

\subsubsection{Stand Diameter and Height Profile}

i. Stand diameter profile

For ease of the comparison and interpretation, the diameter class was formed in to nine groups as: A $(2.6-7.5 \mathrm{~cm})$; $\mathrm{B}$ $(7.6-12.5 \mathrm{~cm}) ; \mathrm{C}(12.6-17.5 \mathrm{~cm}) ; \mathrm{D}(17.6-22.5 \mathrm{~cm}) ; \mathrm{E}$ (22.6-27.5); F (27.6-32.5 cm); G (32.6-37.5 cm); H $(37.5-$ $42.5 \mathrm{~cm})$ and $\mathrm{I}(>42.6 \mathrm{~cm})$. The species density distribution by diameter class was tabled in Annex 6. The result of the analysis of the diameter profile data indicated that about $91.9 \%(\mathrm{~N}=31)$ of the tree/shrub species are those species which have fallen in diameter class $\mathrm{A} ; 3.2 \%(\mathrm{~N}=22)$ in diameter class $\mathrm{B} ; 1.9 \%(\mathrm{~N}=15)$ in diameter class $\mathrm{C}$;
$1.2 \%(\mathrm{~N}=17)$ in diameter class $\mathrm{D} ; 0.4 \%(\mathrm{~N}=12)$ in $\mathrm{E}$ and $0.3 \%(\mathrm{~N}=3)$ in diameter class $\mathrm{F}, 0.2 \%(\mathrm{~N}=6)$ in diameter class $\mathrm{G}, 0.1 \%(\mathrm{~N}=9)$ in diameter class $\mathrm{H} 0.7 \%(\mathrm{~N}=12)$ in diameter class I (See Figure 3). The lowest number of the tree species in diameter classes E, F, G, and $\mathrm{H}$ might indicate that the mature trees that attained the higher diameter size should have been selectively exploited by the local communities for different purposes like house construction and logging. On the other hand, since there is intensive browsing and in addition the area is regularly affected by recurrent drought, these impacts might have also hampered the growth from attaining the higher diameter class.

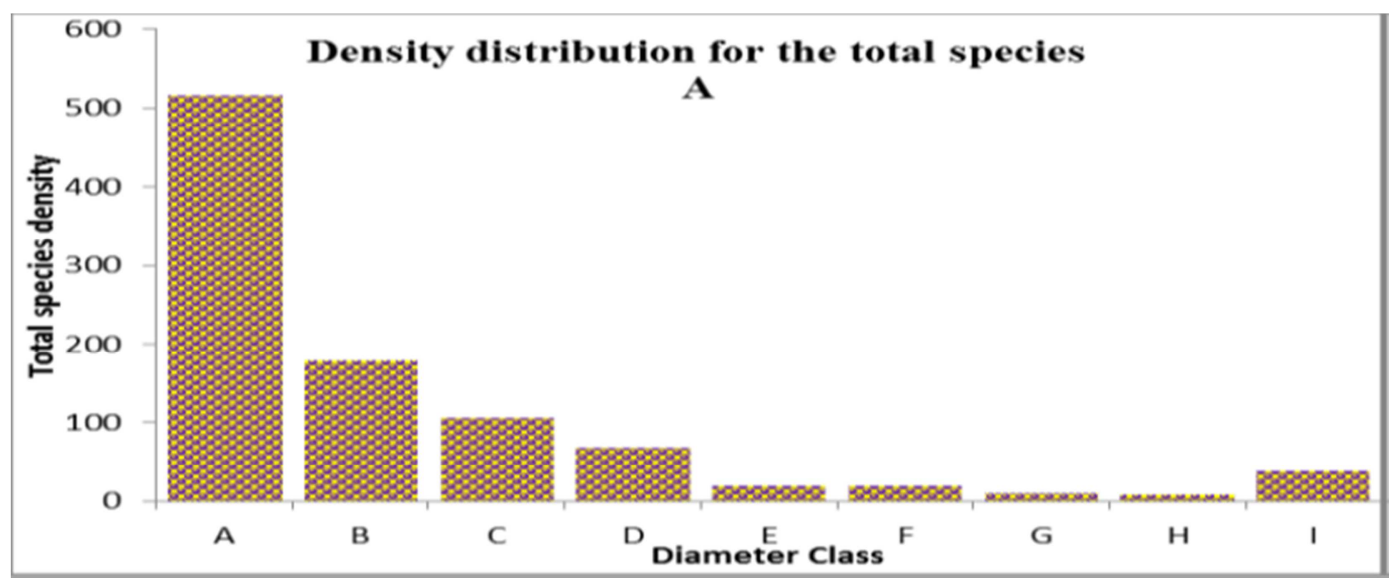

Figure 3. Number and total species density by diameter class. 
ii. Stand Height profile

In determining the stand height profile, the height class was formed in to six groups as: A (5 m), B (5.1-10 m), C (10.1$15 \mathrm{~m}), \mathrm{D}(15.1-20 \mathrm{~m}), \mathrm{E}(20.1-25 \mathrm{~m})$ and $\mathrm{F}(>25 \mathrm{~m})$. The species density distribution by height class was listed in Annex7. The result of the analysis of the height profile data indicated that about $9.2 \%(\mathrm{~N}=34)$ of the tree/shrub species are those species which have fallen in height class $\mathrm{A}, 16.8 \%(\mathrm{~N}=26)$ in height class $\mathrm{B}, 58.1 \%(\mathrm{~N}=14)$ in $\mathrm{C}$ diameter class, $15.1 \%(\mathrm{~N}=15)$ in height class $\mathrm{D}, 0.7 \%(\mathrm{~N}=12)$ in height class $\mathrm{E}$ and $0.1 \%(\mathrm{~N}=6)$ in height class F (See Figure 4). This depicts that the majority of the species belongs to the middle height class. The possible reason could be that intensive browsing and over shadow large trees the determinants for the appearing of the majority of the tree/shrub species in the lower height class.

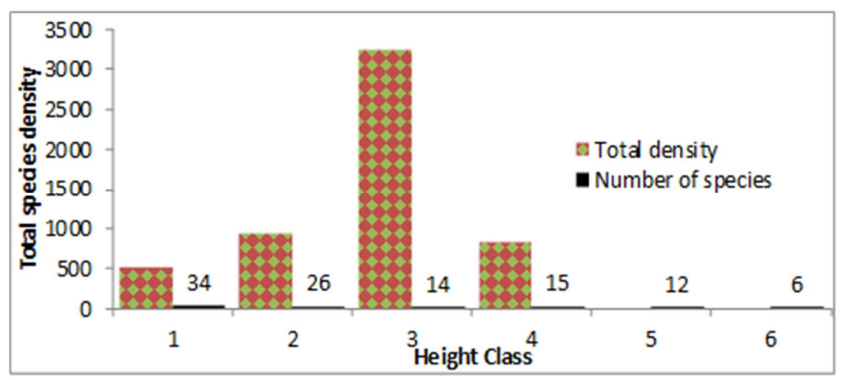

Figure 4. Number and total species density by height class.

\subsubsection{Basal Area and Dominance of Woody Plant Species}

The total basal area for the inventoried woodland is $1.36 \mathrm{~m}^{2}$ per ha. As listed in Annex 8, the biggest basal area recorded was for Schefflera abyssinica $\left(0.23 \mathrm{~m}^{2} \mathrm{ha}^{-1}\right)$ while the largest dominance and relative dominance was for Arundinaria alpina (14.17 and $41.87 \%$ respectively). The top five dominant woody plant species were Arundinaria alpina, Apodytes dimidiata, Euphorbia abyssinica, Allophylus abyssinicus and Hagenia abyssinica respectively within the range of 14.17 1.55. Here the number of stems of a species plays a crucial role for a certain species is dominant or not besides the mean basal area of the species. The basal area was not recorded for about $41.1 \%$ of the woody plant species inventoried. This is because the DBH of the majority of the species was in the lowest diameter class $(2.6-7.5 \mathrm{~cm})$. Conversely, it is only for about $58.9 \%$ of the species that the basal area was recorded that ranges between $0.01-0.23 \mathrm{~m}^{2} \mathrm{ha}^{-1}$. This shows that both the basal areas per species and the total were small. This could be due to the stunted diameter growth of the woody plant species in the dry land areas because of both the ecological factors (moisture deficit and high temperature) and intensive forest disturbance due to browsing, grazing and wood exploitation for house construction.

\subsubsection{Important Value Index (IVI)}

The important value index of the species indicates how dominant is the species in a certain area and hence helps to compare ecological importance of the species in vegetations [4]. Here in the inventoried Gechi In-situ conservation site forest, the species IVI varies between $0.38-131.48$ as tabled in Annex 9. It is lowest for Amedmado and Myrsine africana while it is highest for Arundinaria alpina. This reveals that in this forest the species relative frequency, density and dominance differ accordingly. This in turn implies the importance of developing the conservation priority for the existing species in the forest. Thus, to set the priority for the species in Gechi In-situ conservation site forest the result of the IVI analysis was categorized as in Table 5.

Table 5. IVI class and proportion of the woody plant species.

\begin{tabular}{llll}
\hline Species IVI class & Number of species & Total IVI & Proportion (\%) \\
\hline A $(<1)$ & 12 & 6.21 & 2.10 \\
B $(1.1-7)$ & 17 & 61.04 & 20.62 \\
C $(7.1-13)$ & 7 & 65.12 & 22.00 \\
D $(13.1-19)$ & 2 & 32.15 & 10.86 \\
E $(>19.1)$ & 1 & 131.48 & 44.42 \\
Total & 39 & 296 & 100 \\
\hline
\end{tabular}

As it is listed below in Table 6, Only Arundinaria alpina by its own about $44.42 \%$ to the total IVI value, the majority of the species ( $\mathrm{ca} 43.60 \%$ ) are appearing in the IVI class B contributing around $20.62 \%$ to the total IVI. The next dominant species are categorized to the IVI class $\mathrm{C}$ consisting about $22.0 \%$ from the whole IVI. About $30.7 \%$ of species contributes only $2.10 \%$ from the whole IVI value, Apodytes dimidiata and Euphorbia abyssinica only by its own contributed $10.86 \%$ to the total IVI, and hence Arundinaria alpine, Apodytes dimidiata and Euphorbia abysinica is the most frequent and dominant species in the Forest. On the contrary, since Amedmado, Myrsine africana, Acacia abyssinica and Clausena anisata possess the lowest IVI, they do not frequently exist and are the most minor or rare species in the forest. In principle, when a certain species receives the lowest IVI, it entails as it demands high priority for conservation while those species with the highest IVI require only monitoring and management of setting priority for conservation. In accordance with this, eleven species; Amedmado, Myrsine africana, Acacia abyssinica and Clausena anisata Maytenus arbutifolia, Vernonia amygdalina, Solanecio gigas, Hibiscus macaranthus, Buddleja polystachya, Erica arborea, and Hypericum revolutum demands high priority for conservation. The remaining 28 species needs monitoring and management efforts. According to their IVI Class, the inventoried woody plant species were listed in Table 6. 
Table 6. Woody plant species under the IVI classes.

\begin{tabular}{llllll}
\hline No & A (<1) & No & & No & C (7.1-13) \\
\hline 1 & Erica arborea & 14 & Vernonia auriculifera & 28 & Bersama abyssinica \\
2 & Buddleja polystachya & 15 & Myrica salicifolia & 29 & Measa lanciolata \\
3 & Hibiscus macaranthus & 16 & Osyris quadripartita & 30 & Nuxia congesta \\
4 & Solanecio gigas & 17 & Ekebergia capensis & 31 & Allophylus abyssinicus \\
5 & Vernonia amygdalina & 18 & Pittosporum viridiflorum & 32 & Prunus africana \\
6 & Maytenus arbutifolia & 19 & Erythrina brucei & 33 & Maytenus obscura \\
7 & Clausena anisata & 20 & Ficus sur & 34 & Hagenia abyssinica \\
8 & Acacia abyssinica & 21 & Schefflera abyssinica & 35 & Apodytes dimidiata \\
9 & Amedmado & 22 & Dovyalis abyssinica & 36 & Euphorbia abyssinica \\
10 & Myrsine africana & 23 & Discopodium penninervium & E $(>19.1)$ & \\
& B (1.1-7) & 24 & Dombeya torrida & 37 & Arundinaria alpina \\
11 & Brucea antidysenterica & 25 & Croton macrostachyus & & \\
12 & Dovyalis verrucosa & 26 & Acanthus sennii & & \\
13 & Rosa abyssinica & 27 & Protea gaguedi & & \\
\hline
\end{tabular}

\subsubsection{Species Population Structure}

The pattern of diameter size-class distribution has often been used to represent the population structure of a forest [8]. This is because the pattern of diameter class distribution connotes the general trends of population dynamics and recruitment process of a given species. This was depicted by the evaluation of the diameter class total species density distribution as an inverted $\mathrm{J}$ shape curve (Figure 5, A), which shows a pattern where a total species density distribution has the highest density in the lower diameter class and a gradual decrease towards the higher classes.
The evaluation of selected individual species also revealed two main patterns of population distribution. These are 1) inverted Jshape curve for Prunus Africana and Nuxia congesta, in similar to the general trend of the diameter class total density distribution, this shows the pattern which has the highest species density distribution in the lower diameter class and a gradual decrease towards the higher classes; 2) bell-shaped curve for Allophylus abyssinicus and Euphorbia abyssinica, which is a type of density distribution in which it is high in the middle diameter classes and lower in the lower and higher diameter classes (Figure 5: C, D).

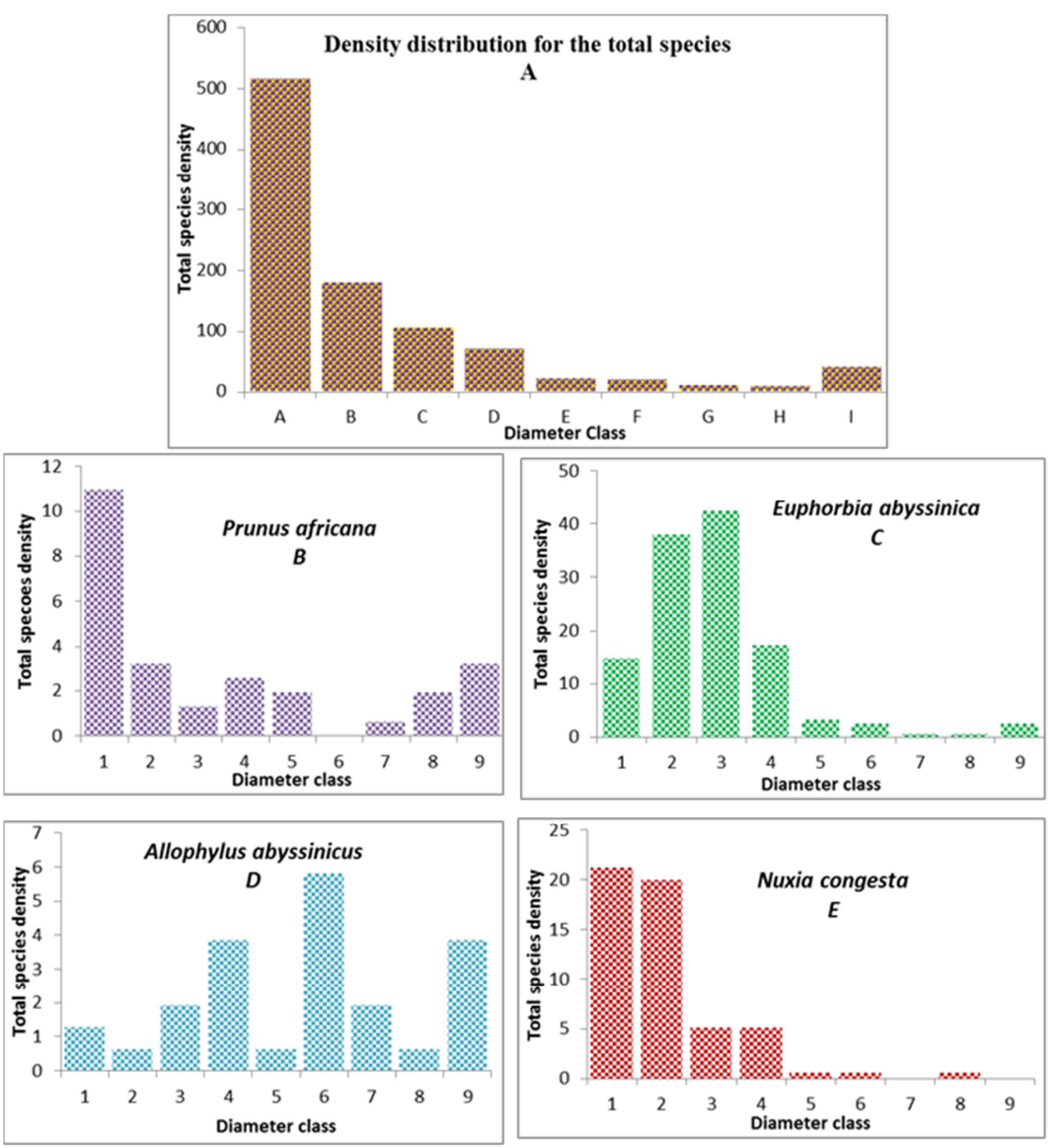

Dbh class: $1=2.6-7.5 \mathrm{~cm} ; 2=7.6-12.5 \mathrm{~cm} ; 3=12.6-17.5 \mathrm{~cm} ; 4=17.6-22.5 \mathrm{~cm} ; 5=22.6-27.5 \mathrm{~cm} ; 6=27.6-32.5 \mathrm{~cm} ; 7=32.6-37.5 \mathrm{~cm} ; 8=37.6-42.5 \mathrm{~cm} ; 9=>42.6 \mathrm{~cm}$

Figure 5. Diameter class density distribution o selected tree species. 
The result of the height class analysis also depicted that there is a higher total density in the middle classes and then this decreases towards the higher and lower height classes (Figure 6). Hence, the pattern of the height class density distribution is showing the declining trend when it goes from the lower to the higher class. In this regard, similar kind of population pattern was also obtained by Feyera Senbeta (2006) [7] in Afromontane rainforest areas indicating a lower proportion of individuals in the lowest height class and few individuals in the middle height class.

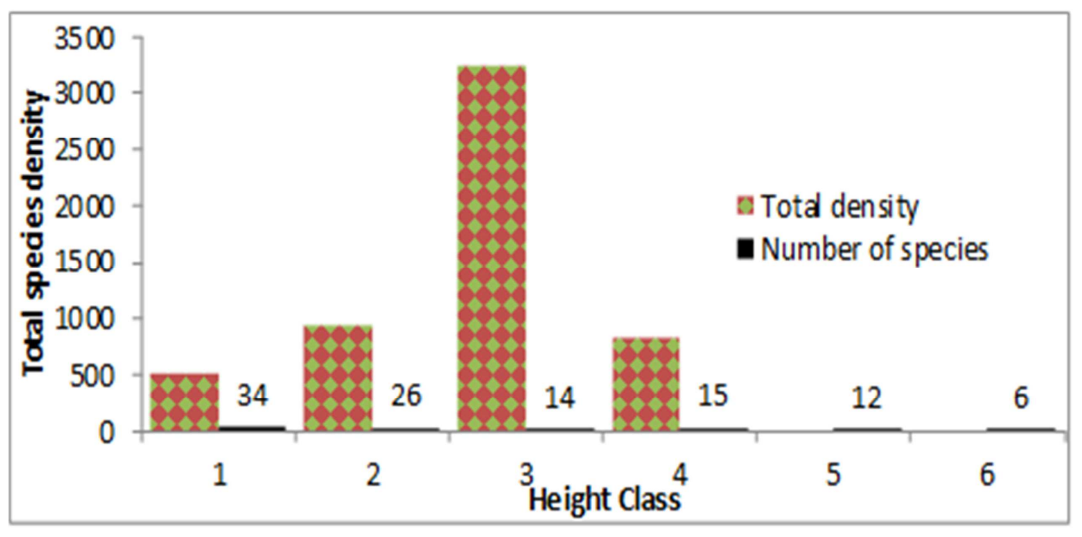

Height class: $1=<5 \mathrm{~m} ; 2=5.1-10 \mathrm{~m} ; 3=10.1-15 \mathrm{~m} ; 4=15.1-20 \mathrm{~m} ; 5=20.1-25 \mathrm{~m} ; 6=>25 \mathrm{~m}$;

Figure 6. Height class density distribution of the woody plants.

The population structure of the species was grouped as follows for the sake of establishing the conservation priority for each species. To group these woody plant species the criteria used were reproduction and recruitment status of the species in the vegetation. Reproduction refers generally to the regeneration status while the recruitment is to mean the appearing of the species in different diameter classes or in the next growth stage. Hence, based on these; the species were categorized as group 1 if both reproduction and recruitment is bad, as group 2 if reproduction is good but recruitment is bad and group 3 if reproduction as well as recruitment is good. Accordingly, the species were listed in Table 7.

Table 7. List of woody plant species by population structure.

\begin{tabular}{llll}
\hline No. & Group 1 & Group 2 & Group 3 \\
\hline 1 & Buddleja polystachya & Maytenus obscura & Dovyalis verrucosa \\
2 & Clausena anisata & Osyris quadripartita & Nuxia congesta \\
3 & Allophylus abysinicus & Myrsine africana & Measa lanciolata \\
4 & Pittosporum viridiflorum & Discopodium penninervium & Brucea antidysenterica \\
5 & Dovyalis abyssinica & Hypericum revolutum & Euphorbia abyssinica \\
6 & & Dombeya torrida & Arundinaria alpina \\
7 & & Protea gaguedi & Vernonia auriculifera \\
8 & & Rytigynia neglecta & Bersama abyssinica \\
9 & & Prunus africana & \\
\end{tabular}

\subsection{Regeneration Status}

The seedling status was recorded for 23 woody plant species which belong to 22 genera and 15 families. This becomes about $58.69 \%$ when compared to the total matured woody plant species richness inventoried. Moreover, the total seedlings density per ha was 1508.04. In terms of species, Maytenus arbutifolia, Bersama abyssinica, Prunus africana, Arundinaria alpine, Measa lanciolata, Euphorbia abyssinica and Rytigynia neglecta respectively share the highest seedlings density in the forest. And while it is the least for Dovyalis abyssinica, Osyris quadripartita, Dombeya torrida and Allophylus abyssinicus woody plant species. In general, this implies that the regeneration status was low and the profound reason could be the intensive trampling by livestock while browsing and grazing in the forest that compact the soil and thereby reduces the germination of the seeds from the soil seed bank. On top of this, they will cause the physical damage on the seedlings by peeling during grazing and browsing. On the other hand, 26 woody plant species existing at the sapling stage were recoded. This is $56.52 \%$ from the total tree/shrub species inventoried. These are grouped to 24 genera and 17 families. Besides, in terms of the individual stems per ha or density, 2387.11 stems per ha were recorded as saplings. Nevertheless, there are about 20 species which neither appears in the seedling or sapling stages. These are listed in Table 8 . Their seedlings and saplings, as discussed above, could be related with the forest disturbance besides the environmental catastrophes like the occurrence of develop seed maturity. Therefore, it demands high priority to ensure the regeneration of these species and thereby conserve in a sustainable way. Similarly, monitoring and conservation is also needed for those 
species which have had low regeneration status.

Table 8. Woody plant species whose seedlings and saplings were not recorded.

\begin{tabular}{lllll}
\hline No. & Scientific name & Local name & Family & Habit \\
\hline 1 & Amedmado & & & Tree \\
2 & Acacia abyssinica & Bazira girar & Fabaceae & Shrub \\
3 & Acanthus sennii & Kosheshile & Acanthaceae & Tree \\
4 & Apodytes dimidiata & Dong & Icacinaceae & Liana \\
5 & Clematis longicauda & Azo harege & Ranunculaceae & Tree \\
6 & Croton macrostachyus & Bisana & Euphorbiaceae & Tree \\
7 & Ekebergia capensis & Lol & Meliaceae & Liana \\
8 & Embelia schimperi & Enkoko & Myrsinaceae & Shrub \\
9 & Erica arborea & Aseta & Ericaceae & Tree \\
10 & Erythrina brucei & Korech & Fabaceae & Tree \\
11 & Ficus sur & Moraceae & Tree \\
12 & Hagenia abyssinica & Kola & Rosaceae & Shrub \\
13 & Hibiscus macaranthus & Yewsha nacha & Myricaceae & Tree \\
14 & Myrica salicifolia & Shinet & Rosaceae & Liana \\
15 & Rubus apetalus & Enjori & Rosaceae & Liana \\
16 & Rubus steudneri & Enjori & Araliaceae & Tree \\
17 & Schefflera abyssinica & Getema & Usteraceae & Shrub \\
18 & Solanecio gigas & Both & Asteraceae & Liana \\
19 & Urera hypselodendron & Lankuso & Tree \\
\hline
\end{tabular}

The general grouping of the woody plant species was undertaken based on the criteria that if the species are totally absent in seedlings and saplings or in the regeneration list at all they were categorized as group 1; as group 2 if density is between 0.1-50 and group 3 if $>50$ according to the list put in Table 9 .

Table 9. List of woody plant species grouped by regeneration status.

\begin{tabular}{llll}
\hline No & Group 1 & Group 2 & Group 3 \\
\hline 1 & Amedmado & Pittosporum viridiflorum & Bersama abyssinica \\
2 & Acacia abyssinica & Myrsine africana & Vernonia auriculifera \\
3 & Acanthus sennii & Osyris quadriparta & Maytenus arbutifolia \\
4 & Apodytes dimidiata & Allophylus abyssinicus & Prunus africana \\
5 & Clematis longicauda & Rubus apetalus & Arundinaria alpina \\
6 & Croton macrostachyus & Capparis tomentosa & Euphorbia abyssinica \\
7 & Ekebergia capensis & Clausena anisata & Brucea antidysenterica \\
8 & Embelia schimperi & Buddleja polystachya & Rytigynia neglecta \\
9 & Erica arborea & Embelia schimperi & Measa lanciolata \\
10 & Erythrina brucei & Maytenus obscura & Protea gaguedi \\
11 & Ficus sur & Dovyalis abyssinica & Nuxia congesta \\
12 & Hagenia abyssinica & & Dombeya torrida \\
13 & Hibiscus macaranthus & & Dovyalis verrucosa \\
14 & Myrica salicifolia & & Hypericum revolutum \\
15 & Rubus apetalus & & Clutia abyssinica \\
16 & Rubus steudneri & & Discopodiumpenninervium \\
17 & Schefflera abysinica & & Rosa abyssinica \\
18 & Solanecio gigas & & \\
19 & Urera hypselodendron & & \\
20 & Vernonia amygdalina & & \\
\hline
\end{tabular}

\subsection{Vegetation-Environment Relationship}

\subsubsection{Floristic Richness by Altitude}

The altitudinal range of Gechi in-situ conservation site forest is between $2543-2806 \mathrm{~m}$ a. s. 1 . and thus belongs to the Highland agro-ecological zone as defined above $2500 \mathrm{~m}$ a. s. 1. Consequently, the area has no wide altitudinal variation that affects much the distribution and species richness of woody plant species.

\subsubsection{Floristic Richness by Aspect}

The result of the study pointed out that the species distribution varies with aspects. In accord with this, about
$31.5 \%$ of the species were recorded from the southwest, $25.2 \%$ from northeast, $22.8 \%$ from north, $12.6 \%$ from south and $7.9 \%$ on northwest direction of the woodland topographic feature. However, no species was occurred on three aspects: west, east and southeast. In terms of the individual species, maximum number of woody plant species (14) was inventoried on the Southwest direction followed by east and northeast aspects respectively as depicted in Figure 7. This entails that the floristic composition of plant species are affected by aspects and vary accordingly. 


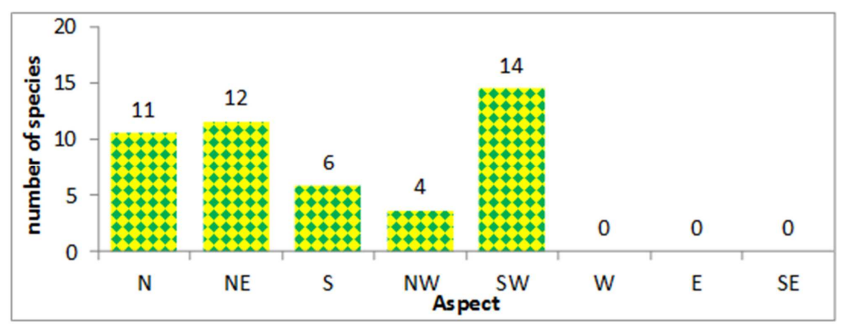

Figure 7. Number of species recorded as per the topographic aspects.

\subsubsection{Floristic Richness by Slope Gradients}

The species occurrence analysis by slope gradient revealed that $8.7 \%$ of the total woody plant species inventoried was recorded from slope gradient class $\mathrm{A} ; 32.6 \%$ from class $\mathrm{C}$; $28.3 \%$ from D $26.1 \%$ from class $\mathrm{E}$ and finally $4.3 \%$ of the total species was recorded from slope gradient class $\mathrm{F}$ (shown in Annex 13). The number of woody plant species composition or distribution was higher at slope gradient class C (11-30\%). This slope gradient class is a landscape characterized by gentle to moderate slope where usually the soil nutrient movement is slow, while aeration and infiltration is high. This has created the optimum land suitability for plant growth. On the contrary, the species richness is lowest at slope gradient class F (31-50\%). This is because such type of topography is characterized by steep slope and the gravitational movement of soil nutrient is high besides the high impact of run off on soil and as a result, soil moisture content is low particularly in low land areas. This worsens the growth and regeneration of the plant species.

The relationship between the species richness and slope gradient was non-linear and this is moderately explained by $55 \%(\mathrm{R} 2=0.5524)$. It is a bell-shaped type of distribution. At the lower slope gradient class the number of species is few and it increases towards the moderate slope class and then decreases as slope gradient rises to steep slope. This result agrees with the finding of Feyera Senbeta (2006) [7] that pointed out the relationship between topographic features and species abundance is non-linear in afromontane rainforest areas. Therefore, this confirms that the topographic features significantly affect the species composition and distribution.

\section{Measures Proposed for the Genetic Conservation of Woody Plant Species}

Conservation programs are what geographical regions to protect in order to maintain the most biological diversity. The term biodiversity hotspot was coined by the study [9]. A good conservation measure is complementarity, where the species complement of a reserve or area is identified and then further sites are found that add the greatest number of new species; this is similar to the portfolio approach [13]. Another method using integer linear programming to choose the optimal set of sites (maximal-covering-location; the study [3] is limited to small datasets and does not achieve the greatest conservation gain for the fewest additional sites. Clearly, combining an ecosystem portfolio approach with a richness or endemism assessment would be effective, but differing approaches are needed according to the conservation goal and data availability. [5] Rarity and endemicity have been used to define hotspots and species richness and endemism have been used to rank countries [10]. Hotspots are also defined as those areas with the greatest number of threatened species.

Based on the above discussion we conclude our conservation strategy on population structure (PS), regeneration status (RS) and IVI of the woody plant species, the conservation priority was proposed as summarized in Table 10 .

Table 10. Woody plant species prioritized according to IVI, PS and RS groups.

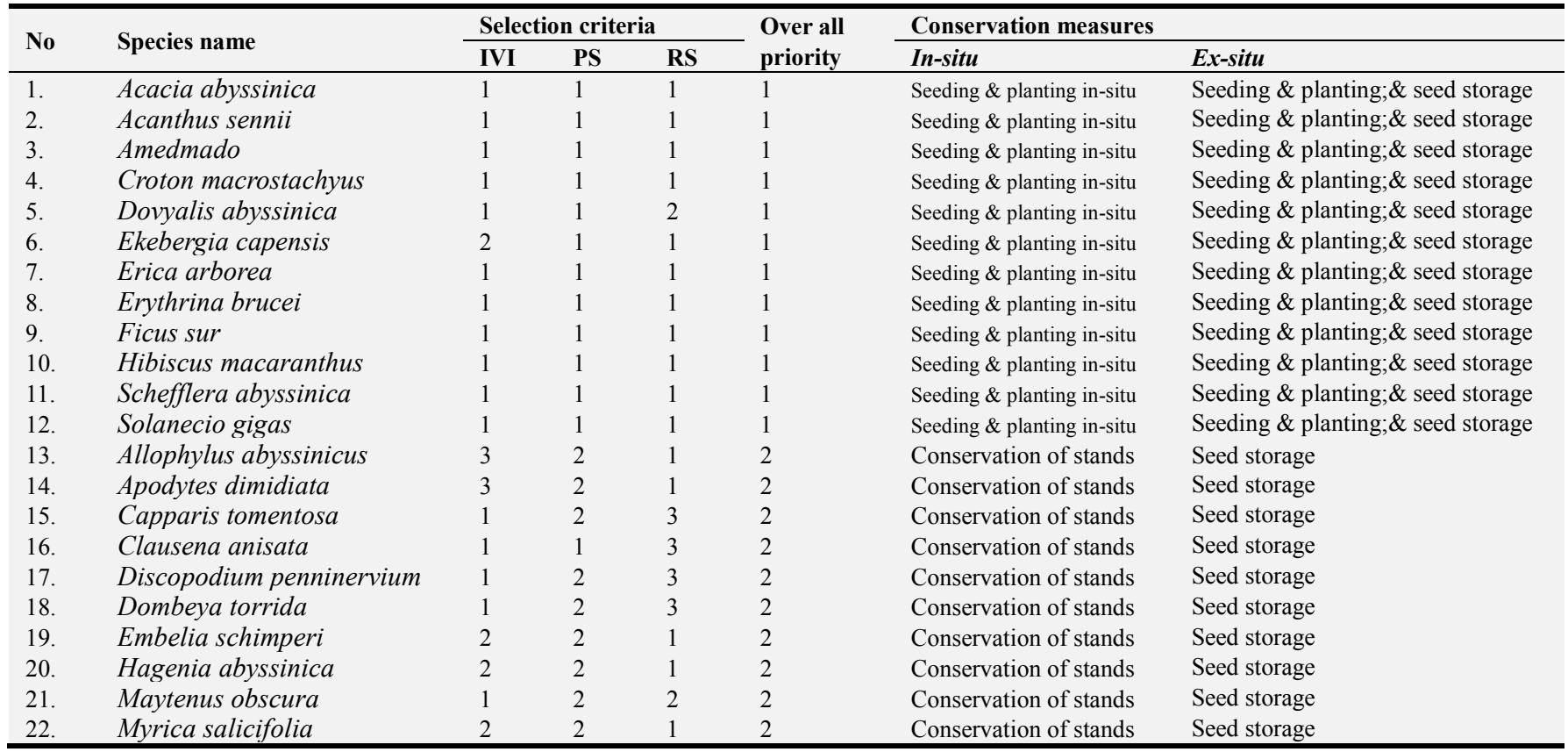




\begin{tabular}{|c|c|c|c|c|c|c|c|}
\hline \multirow{2}{*}{ No } & \multirow{2}{*}{ Species name } & \multicolumn{3}{|c|}{ Selection criteria } & \multirow{2}{*}{$\begin{array}{l}\text { Over all } \\
\text { priority }\end{array}$} & \multicolumn{2}{|l|}{ Conservation measures } \\
\hline & & IVI & PS & RS & & In-situ & Ex-situ \\
\hline 23. & Myrsine africana & 1 & 2 & 2 & 2 & Conservation of stands & Seed storage \\
\hline 24. & Osyris quadripartita & 2 & 2 & 2 & 2 & Conservation of stands & Seed storage \\
\hline 25. & Pittosporum viridiflorum & 2 & 1 & 2 & 2 & Conservation of stands & Seed storage \\
\hline 26. & Protea gaguedi & 1 & 2 & 3 & 2 & Conservation of stands & Seed storage \\
\hline 27. & Vernonia amygdalina & 2 & 1 & 1 & 2 & Conservation of stands & Seed storage \\
\hline 28. & Buddleja polystachya & 1 & 2 & 2 & 2 & Conservation of stands & Seed storage \\
\hline 29. & Arundinaria alpina & 3 & 3 & 3 & 3 & Conservation of stands & Seed storage \\
\hline 30. & Dovyalis verrucosa & 2 & 3 & 2 & 3 & Conservation of stands & Seed storage \\
\hline 31. & Bersama abyssinica & 3 & 3 & 3 & 3 & Conservation of stands & Seed storage \\
\hline 32. & Brucea antidysenteric & 2 & 3 & 3 & 3 & Conservation of stands & Seed storage \\
\hline 33. & Clematis longicauda & 2 & 2 & 3 & 3 & Conservation of stands & Seed storage \\
\hline 34. & Clutia abyssinica & 2 & 2 & 3 & 3 & Conservation of stands & Seed storage \\
\hline 35. & Euphorbia abyssinica & 3 & 3 & 3 & 3 & Conservation of stands & Seed storage \\
\hline 36. & Hypericum revolutum & 3 & 2 & 3 & 3 & Conservation of stands & Seed storage \\
\hline 37. & Maytenus arbutifolia & 3 & 2 & 2 & 3 & Conservation of stands & Seed storage \\
\hline 38 & Measa lanciolata & 3 & 3 & 3 & 3 & Conservation of stands & Seed storage \\
\hline 39 & Nuxia congesta & 3 & 3 & 3 & 3 & Conservation of stands & Seed storage \\
\hline 40 & Prunus africana & 3 & 2 & 3 & 3 & Conservation of stands & Seed storage \\
\hline 41 & Rosa abyssinica & 2 & 2 & 3 & 3 & Conservation of stands & Seed storage \\
\hline 42 & Rytigynia neglecta & 3 & 2 & 3 & 3 & Conservation of stands & Seed storage \\
\hline 43 & Vernonia auriculifera & 1 & 3 & 3 & 3 & Conservation of stands & Seed storage \\
\hline
\end{tabular}

\section{Conclusion}

The Gechi In-situ conservation forest belongs to the moist evergreen afromontain forest type of ecosystem. The inventoried Gechi In-situ site forest (within the altitudinal gradient of 2545- $2830 \mathrm{~m}$ a. s. 1.) consists of 46 woody plant species that belongs to 42 genera and 32 families. This implies that the vegetation is comprised of high species richness and diversity. However, similar to the other areas of the forest ecosystem of Ethiopia, this forest is also under population pressure largely because of the Highland farming system is dominated in the area. The main attributing factors towards the disturbance of the forest are browsing, grazing and selective exploitation of mature highland bamboo for house construction and fence construction. These factors have caused the absence of the floristic composition at the higher diameter and height classes. The regeneration status of most economically important woody plant species is low. This raises the question of 'Could this vegetation continue in a perpetual way keeping its optimal productivity without losing its floristic richness?' To answer this it needs further investigation on the vegetation ecosystem functioning (that includes soil and soil seed bank), the impacts of climate change and human impacts. For the time being, however; the result of the IVI analysis showed that Myrsine africana, Amedmado, Acacia abyssinica, Clausena anisata, Maytenus obscur, Vernonia auriculifera, Solanecio gigas, Hibiscus macaranthu, Buddleja polystachya, Erica arborea and Hypericum revolutum deserved the lowest IVI value and were categorized in IVI class 1 . Therefore, setting high priority is needed to conserve these endangered woody plant species. The conservation strategy could follow either the ex-situ or field gene bank or both conservation systems. The other remaining species require mentoring and management efforts in a sustainable way.

\section{Acknowledgements}

The paper was funded by Ethiopian Biodiversity Institute. We are glad to Sekela District local communities living around the forest in providing valuable information on the forest and District government officials for their kind assistance in collecting the data.

\section{Conflicts of Interest}

The authors declare that there is no conflict of interest and the funder had no role in the design, collection, and analyses of data as well in the writing of the manuscript.

\section{References}

[1] Azene Bekele-Tesema, A. B. B. Tengnäs. 1993. Useful trees and shrubs for Ethiopia. Regional soil conservation unit/SIDA. Ethiopia.

[2] Central Statistics Agency of Ethiopia, 1994 Population census report, Addis Ababa Ethiopia.

[3] Church, R. L., Stoms, D. M., and Davis, F. W. (1996). Reserve selection as a maximal covering location problem. Biol. Conservation 76, 105-112.

[4] Curtis J. T. and R. P. McIntosh. 1951. An Upland continuum in the praine Forest Border region of Wisconsin, Ecology 32: 476-496.

[5] Hunter, M. L., Jr. (1996). Fundamentals of Conservation Biology. Blackwell Science, Cambridge, Massachusetts.

[6] MEFCC (Ministry of Environment, Forestry and Climate Change). 2018. Vol I Situation analysis, Addis Ababa, Ethiopia.

[7] Feyera Senbeta.2006. Biodiversity and Ecology of Afromontane rainforests with wild Coffea arabica L. populations in Ethiopia. $\mathrm{PhD}$ thesis, Cuvillier Verlag Gottingen University, Germany. 
[8] Khan M. L., Rai J. P. and R. S. Tripathi. 1987. Population structure of some tree species in distributed and protected subtropical forests of northeast India. Acta Oecologia 8: 247-255.

[9] Myers, N. (1990). Threatened biotas: "Hotspots" in tropical forests. Environmentalist 8, 1-20.

[10] Mc Neely, J. A., Miller, K. R., Reid, W. V., Mittermeier, R. A., and Werner, T. B. (1990). Conserving the World's Biological Diversity. International Union for Conservation of Nature and Natural Resources/World Resources Institute/Conservation International/ World Wildlife Fund-U.S./World Bank, Gland, Switzerland/ Washington, D.C.

[11] Rosenzweig, M. L. (1995). Species Diversity in Space and Time. Cambridge University Press, Cambridge, United Kingdom.

[12] SWADO (Sekella Woreda Agricultural Development Office). 2008. The Leaflet of the Sekella Woreda Agricultural Development Office.
[13] Swingland, I. R. (1997). Global conservation and the sciences: People, policy and pennies. In Conservation, Restoration and Management of Tortoises and Turtles (J. Van Abbema, ed.), pp. 453-464. New York Turtle and Tortoise Society, New York.

[14] Thomas, R. (1992). Genetic diversity. In Global Biodiversity: Status of the Earth's Living Resources: (World Conservation Monitoring Centre, eds.), pp. 1-6. Chapman and Hall, London.

[15] Whittaker, R. H. (1972). Evolution and measurement of species diversity. Taxon 1, 213-251.

[16] Zerihun Woldu. 1999. Forests in the Vegetation Types of Ethiopia and their Status in the Geographical Context. In: Proceedings of Forest Genetic Resources Conservation: Principles, Strategies and Actions. The National Forest Genetic Resources Conservation Strategy Development Workshop. June, 21-22, 1999, Addis Ababa, Ethiopia. 